\title{
UMA OBRA REFERÊNCIA PARA PROFESSORES RURAIS: ESCOLA PRIMÁRIA RURAL
}

\author{
Dóris Bittencourt Almeida
}

\begin{abstract}
RESUMO
Este trabalho analisa a obra Escola Primária Rural, produzida pela professora e técnica rural Ruth Ivoty Torres da Silva, no início da década de 1950, no Rio Grande do Sul. Os textos do livro revelam representações que foram construídas sobre o mundo rural; representações acerca dos significados da escola, dos professores, dos alunos e das populações rurais, de um modo geral. $\mathrm{O}$ estudo em questão insere-se no campo de investigações da História da Educação, sendo esta uma componente fundamental da história das práticas culturais e do cotidiano social. A pesquisa identifica-se com os pressupostos teóricos da História Cultural, corrente historiográfica que pretende buscar alternativas à história de cunho tradicional. O trabalho também se inscreve no campo da história das práticas de leitura e escrita, tendo como referenciais as concepções da cultura escrita enquanto produção discursiva de um determinado tempo e lugar. Para além da apresentação dos temas abordados no livro, a investigação está especialmente interessada nos significados da difusão dos discursos divulgados pela obra, nos processos de subjetivação provocados pelos textos escritos e suas possíveis influências nos modos como os professores rurais pensavam, agiam e se expressavam nos espaços de construção de suas identidades. Entende-se que o livro Escola Primária Rural constitui-se em um documento significativo para a História da Educação, por abordar questões relevantes acerca da problemática do ensino nas regiões campesinas, relatar experiências de atividades rurais desenvolvidas em diferentes escolas e propor sugestões de atividades empíricas relacionadas ao trabalho pedagógico do professor.
\end{abstract}

Palavras-chave: Educação rural. Formação docente rural. Práticas de leitura e escrita.

\section{ABSTRACT}

\section{A WORK REFERENCE FOR RURAL TEACHERS: RURAL PRIMARY SCHOOL}

This paper analyzes the book Rural Primary School written by the professor and rural technician Ruth Ivoty Torres da Silva, in the early 1950s, in Rio Grande do Sul. The text of the book reveals representations constructed about the rural world; representations about the meanings of school, about teachers, students, rural populations in general. The study in question falls within the field of investigations of History of Education, which is a key component of the history of cultural practices and everyday society. It identifies itself within the theoretical assumptions of

\footnotetext{
* Doutora em Educação (PPGEdu/UFRGS). Professora da Faculdade de Educação da Universidade Federal do Rio Grande do Sul. Endereço para contato: Rua Lopo Gonçalves, n 218, ap. 601, Bairro Cidade Baixa, Porto Alegre. CEP: $90050-350$. almeida.doris@gmail.com
} 
Cultural History, current historiographical approach which looks for alternatives to the traditional dynamic of history. The work also falls within the field of history of practices of reading and writing, taking as reference the conceptions of literacy as a discursive production of a particular time and place. Besides the presentation of the topics covered in the book, our research is particularly interested in the meanings of the dissemination of speeches broadcasted, the subjective processes provoked by texts and their possible influences in the ways rural teachers thought, acted and expressed themselves in the spaces where they build their identities. We understand that the book Rural Primary School constitutes a significant document in the history of education as it addresses relevant issues regarding the problem of education in peasant regions, relates experiences of rural activities undertaken in different schools and proposes empirical activities related to the pedagogical work of teachers.

Keywords: Rural education. Teacher training rural. Practices of reading and writing.

\section{A autora e sua obra: aproximações}

Este trabalho analisa a obra Escola Primária Rural, produzida pela professora e técnica rural Ruth Ivoty Torres da Silva, no início da década de 1950, no Rio Grande do Sul. O estudo insere-se no campo de investigações da História da Educação, identifica-se com os pressupostos teóricos da História Cultural ${ }^{1}$ e se inscreve no campo da história das práticas de leitura e escrita, tendo como referenciais as concepções da cultura escrita enquanto produção discursiva de um determinado tempo e lugar.

O livro em questão constitui-se em um documento significativo para a História da Educação, por reconstruir o imaginário educacional rural, analisar o ensino nas regiões campesinas, relatar experiências desenvolvidas em diferentes escolas e propor atividades relacionadas ao trabalho pedagógico do professor.

Para além da apresentação dos temas abordados no livro, a investigação está especialmente inte-

\footnotetext{
Stephanou e Bastos (2005) apontam a possibilidade de estabelecimento de íntimas relações entre a História Cultural e a História da Educação, especialmente quando as memórias constituem a documentação privilegiada. As autoras afirmam que a História da Educação é parte integrante da cultura de um povo e, portanto, promove uma compreensão mais fecunda da cultura escolar de determinada época, de determinada instituição. Da mesma forma, Maria Teresa Cunha percebe o alargamento de possibilidades investigativas promovido pela História Cultural e, assim, permite que o historiador produza suas pesquisas "em direção a outros campos do conhecimento, de sujeitos e de objetos até então inexplorados." (CUNHA, 1999, p. 42).
}

ressada nos significados da difusão dos discursos divulgados pela obra, nos processos de subjetivação provocados pelos textos escritos e suas possíveis influências nos modos como os professores rurais pensavam, agiam e se expressavam nos espaços de construção de suas identidades. O professor rural se via projetado nas páginas do livro, por isso acredita-se no forte potencial educativo do trabalho de Ruth Ivoty da Silva.

Ela nasceu em 1913, em São Borja, município do Rio Grande do Sul. Ao longo de sua vida profissional, preocupou-se com a educação rural no Rio Grande do Sul. Participou de cursos na Sociedade Amigos de Alberto Torres, no Rio de Janeiro, foi técnica em educação do Centro de Pesquisas e Orientação Educacional, chegando a ocupar o cargo de Superintendente do Ensino Rural. Também representou o estado em diversos eventos educacionais (SILVA, 1951, p. 246-248).

Metodologicamente, a autora parte de uma visão geral acerca da educação rural aliada à importância da agricultura no Brasil (capítulo 1) e, logo no capítulo seguinte, aborda questões relevantes sobre a problemática do ensino nas regiões campesinas do estado. Comenta as impressões que se tinha acerca das populações rurais, dos professores e dos alunos, fala das características das escolas rurais, sua função social, objetivos, não descuidando da análise da formação docente para o meio rural. Os capítulos 3,4 e 5 destinam-se a auxiliar o professor didaticamente, oferecem sugestões de planos de aulas 
com objetivos, diretrizes, conhecimentos a serem adquiridos, e propõem atividades aos alunos. Ao final de cada capítulo, a autora apresenta a bibliografia consultada, preocupando-se em documentar suas pesquisas com as devidas referências.

No início do livro, explica os fins de seu trabalho:

Não visa este trabalho apresentar novidade em matéria de Educação Rural. Numa tentativa de sistematizar o que tem sido pregado e experimentado naquele terreno é, antes, colaboração modesta, oferecida aos professores que se destinam às escolas primárias de zonas rurais, enquanto este aspecto não for atendido nas escolas de formação de professores, com a extensão que lhe é devida. [...] apesar da boa vontade e do esforço de muitos professores sentimos a necessidade da preparação específica de nosso magistério para uma ação mais decidida nas áreas rurais. Esse é o aspecto que nos animou à presente realização (SILVA, 1951, p. 2).

Possivelmente, ao escrever Escola Primária Rural, Ruth Silva tenha procurado reunir em um livro os textos que produziu ao longo de anos, haja vista escrevia sistematicamente na seção "O ensino rural" da Revista do Ensino (1939 até a década de 1950), produzia textos para os Boletins de Educação Rural (1954 a 1957) e para os Boletins do CPOE. Assim, percebe-se que organizou um material que contempla reflexões acerca das grandes questões que envolvem a educação rural, com o objetivo de que se constituísse em uma fonte de consulta para os docentes rurais.

A Revista do Ensino n ${ }^{\circ} 7$ (1951), apresenta uma nota de divulgação do livro da professora Ruth, evidenciando os problemas enfrentados pelo ensino rural e valorizando a publicação da obra como um instrumento de fundamentação teórica e prática para o magistério:

Trabalhando há anos no sentido de orientar a realização de atividades ou clubes agrícolas no RS, a autora desta obra sentiu, apesar dos esforços e da boa vontade de inúmeros mestres, a necessidade de preparação específica do nosso magistério no setor do Ensino Rural. Publicados agora os resultados de seus estudos, de suas pesquisas e experiências, presta a professora Ruth um inestimável serviço ao magistério, à vida rural e aos interesses nacionais. Dando a esta obra um cunho eminentemente prático, tornou-o a autora acessível a todos quantos queiram conhecer, resolver os problemas da Educação Rural. (p. 89)

O livro teve a sua primeira publicação pela Editora do Globo, em $1951^{2}$. A primeira edição teve uma tiragem de 3 mil exemplares, que circularam pelo Rio Grande do Sul, Bahia, Pernambuco, São Paulo e Rio de Janeiro. Nessa primeira edição, as vendas foram lentas. José Otavio Bertaso, um dos antigos editores da Livraria e Editora do Globo, salienta que era difícil divulgar e fazer com que o livro efetivamente chegasse às escolas rurais, pois a maioria delas não trabalhava com uma quantidade considerável de livros, principalmente aqueles destinados especificamente à educação rural. Segundo Bertaso (2002), essa situação modificou-se em 1966, quando houve então um acordo entre o Ministério da Educação e o USAID (Ajuda Internacional para o Desenvolvimento) para a criação de um programa de bibliotecas e divulgação gratuita de livros, entre eles os que envolviam temas ligados à Educação e à Sociologia. Tal parceria atingiu um conjunto de 4 mil bibliotecas no Brasil e cada uma delas ficou equipada com 360 títulos, aproximadamente.

Dessa forma, foi possível promover mais três edições da Escola Primária Rural durante os anos 1960, sendo a última editada em 1971, com um total de 8 mil exemplares publicados e distribuídos para todo o país. Em razão dessa quantidade de publicações, atualmente ainda é possível encontrá-lo nas livrarias e sebos.

O livro abarca uma quantidade considerável de conhecimentos ao longo de seus cinco capítulos, cumprindo, em tese, sua função de ser um referencial pedagógico para o magistério rural. Parte de uma visão mais teórica, fundamentada nos princípios do ruralismo pedagógico e da Escola Nova, valendo-se das ideias de sociólogos e estudiosos ligados às questões rurais do país, como Alberto Torres, Renato Sêneca Fleury e Fernando de Azevedo, que analisam tanto a problemática rural do

\footnotetext{
2 A Editora Globo foi responsável pela difusão e propagação de inúmeras obras de autores gaúchos. Consegui obter alguns dados mais específicos sobre as edições do livro por meio da colaboração de um dos antigos proprietários, conhecedor de todo o trabalho editorial da Globo, senhor José Otávio Bertaso. Para maiores informações sobre a história da Editora do Globo, consultar Torresini, Elisabeth R. Editora Globo: uma aventura editorial nos anos 1930 e 1940. São Paulo: Edusp, 1999.
} 
país quanto as representações construídas acerca das populações campesinas.

\section{O cenário da educação rural}

As fronteiras que, no passado, separavam claramente os aspectos culturais e geográficos dos meios urbano e rural, hoje se apresentam pouco nítidas. $\mathrm{O}$ século $\mathrm{XX}$ assistiu à transformação de uma sociedade de base eminentemente agrária em uma sociedade industrial, e a cidade assumiu a posição de paradigma dos modelos culturais e sociais. O Brasil era um país nitidamente rural e assim se manteve até a década de 1920, mas, a cada novo período, a tendência irreversível foi o aumento da população urbana e o decréscimo da população rural. As mudanças econômicas e sociais promoveram transfigurações identitárias e, portanto, afirmaram-se as identidades urbanas, uma vez que a cidade tornou-se o ícone da modernidade.

O advento da República, no final do século XIX, delimitou um processo de transformação estrutural na sociedade brasileira, pois a pretensão era inserir o Brasil no contexto da modernidade. As transformações tomaram proporções maiores logo no início do século seguinte, com a afirmação do trabalho assalariado e os melhoramentos urbanos, aliados a um processo da industrialização, ainda que incipiente. A afirmação de uma sociedade marcadamente capitalista exigiu que se buscassem feições mais cosmopolitas e liberais para a educação, ou seja, era preciso que a escola se apresentasse à população como pública, laica e universal. A reorganização do Estado, sob o modelo republicano, promoveu a busca da escolarização como uma necessidade e uma alternativa de adaptação às transformações econômicas, sociais e políticas que vivia o país (GHIRARDELLI JR., 1995, p. 16). O país “modernizava-se", e nisso estavam implicadas as escolhas e os caminhos educacionais percorridos. Assim, o mundo urbano passou a ser o condutor, pautando as decisões políticas e econômicas, tornando-se modelo das referências culturais.

Nesse contexto, o meio rural foi associado às ideias de atraso, de ausência de desenvolvimento e de ignorância de sua população. A educação rural ${ }^{3}$

A educação no meio rural no Rio Grande do Sul é analisada em uma versão ampliada em Almeida (2004). passou a ser vista como um instrumento capaz de aproximar a modernização, de formar, de modelar cidadãos adaptados ao seu meio de origem, mas lapidados pelos conhecimentos endossados pela cultura urbana. De lá que vieram os ensinamentos, tais como conhecimentos de saúde, saneamento, alimentação adequada, administração do tempo, técnicas agrícolas e pastoris modernas, práticas de higienização, todos esses amparados e condizentes com o desenvolvimento científico da sociedade.

Entende-se que a educação rural constituiu-se em um dispositivo de governo da população rural e, neste sentido, o livro Escola Primária Rural era também um dispositivo para formar as populações rurais, colaborando na construção de um determinado éthos do homem rural. A autora defende o papel de redentora da escola rural, na busca da justiça social para alcançar o ideal do progresso e afastar das populações campesinas a ignorância e o descompasso e relação aos meios urbanos.

William Soto (2002) analisa a formação do que ele chama "ideologia urbana e ideologia rural" (p. 110), com base na identificação dos aspectos que caracterizam o rural com a ideia de "atraso" e o urbano com a imagem do "progresso". Produziu-se uma discursividade que depositou na industrialização a possibilidade de eliminar a precariedade que definia o meio rural e seus habitantes. Observa-se que o processo de modernização experimentado pelo país não atingiu somente as cidades, mas expandiu-se para as regiões rurais por meio da mecanização de lavouras, por exemplo. Consequentemente, o cidadão urbano foi erigido como modelo a ser seguido, e seus valores deveriam nortear os padrões de comportamento das populações rurais. A estas restou a apropriação de outros paradigmas econômicos e culturais que, com o passar do tempo, conduziram a um esquecimento de suas próprias referências. Nos dizeres de Soto, "a cidade e o campo são dois polos antagônicos, onde o primeiro terá que superar o segundo como fundamento da nova civilização" (2002, p. 110). Os discursos da época dividiam o mundo entre urbano e rural, civilização e atraso, ciência e ignorância.

Portanto, os anos 1950 e 1960 mostram um cenário educacional brasileiro em que há diferentes sujeitos educacionais inseridos em realidades igualmente distintas. De um lado, a urbanização e 
industrialização que marcavam a vida e a escolarização nas cidades. De outro, alunos, professores e comunidades que partilhavam espaços comuns: o meio rural e a escola rural, com suas dificuldades e seus possíveis encantos. A escola era o lugar diferenciado da comunidade rural, espaço em que o conhecimento endossado pela ciência se fazia presente, lugar em que o aluno convivia com artefatos culturais distintos de suas referências: classes, quadro-negro, livros, cartilhas, revistas, murais, mapas, cartazes, cadernos, lápis, às vezes mimeógrafos, que compunham o ambiente de aprendizagem.

Eram muitos os problemas que marcavam o ensino rural no país. Aos alunos, poderia ser difícil perceber a validade da escola, pois esta seguidamente exigia o afastamento das atividades agrícolas e pastoris que lhes garantiam a subsistência. O Estado, se por um lado parecia acreditar na "predestinação rural do país" (NAGLE, 1974. p. 45 ) e apostar no trabalho dos professores, poderia ter investido mais em políticas públicas que de fato desenvolvessem o ensino rural e a formação pedagógica especificamente direcionada àquela realidade. As posições das autoridades públicas traduziam-se em algumas ações reais, mas não atendiam de modo efetivo às carências do meio rural. O que se observa, assim, é o abandono das populações do campo, que permaneciam desassistidas, afastadas das melhorias educacionais ${ }^{4}$. A autora critica a falta de acesso à escolarização das populações rurais e, da mesma forma, condena o ensino livresco, desvinculado da realidade do homem rural.

Com relação aos professores rurais, cabe ressaltar que, via de regra, estavam despreparados para a função, não tinham formação específica para o trabalho ou para enfrentar as possíveis adversidades da profissão. E, mesmo que estudassem em instituições de formação docente rural, a titulação não tinha o alcance profissional garantido pelas escolas normais das cidades, tendo em vista que o curso normal rural equivalia ao curso ginasial. Tudo isso fez com que os professores rurais constituíssem outro grupo, hierarquicamente inferior, periférico, talvez, no conjunto do magistério público estadual.

4 Sobre estas questões, ver também ALMEIDA (2001), capítulos 1 e 2 .
No campo da historiografia da educação, em alguma medida, esses sujeitos, alunos e professores rurais, carregam marcas de esquecimento. Tal situação, que caracteriza a história da educação rural, mostra o distanciamento que se tem em relação ao meio rural, em uma cultura que hoje é eminentemente urbana. Parece haver uma amnésia coletiva em relação ao fato de que, até há pouco tempo, o Brasil tinha sua economia, sua população e seus valores culturais diretamente vinculados às áreas rurais. Então, o que se percebe é o desenvolvimento de um processo que coloca as populações rurais em uma situação de exclusão social. Ulpiano de Meneses (1999), ao analisar a dimensão política da memória, reflete acerca dessa amnésia que caracteriza nossa sociedade, em que prevalece o efêmero, o transitório, em que não há espaço para a memória de longa duração.

\section{Produzem-se sujeitos: os discursos acerca da educação rural}

Os professores rurais foram constituídos por meio de práticas historicizadas e das inter-relações de diferentes discursos que se difundiam e se sustentavam na sociedade brasileira das décadas passadas. Quando professores identificam-se com os temas circulantes, eles se tornam assujeitados a esses discursos, por um processo de adesão ou de identificação, e começam a se reconhecer e, paralelamente, a se constituir como sujeitos. Segundo Pinto (1989), um discurso só tem capacidade de exercer poder quando consegue e tem capacidade de responder a demandas, de se inserir no conjunto de significados da sociedade, definindo posições e lugares dos sujeitos, até porque sabemos que a capacidade de um discurso de exercer um poder, de permanecer, é sempre provisória, precisa sempre estar se reinventando para se adaptar a novos contextos sociais. Nesta perspectiva escolhida, o sujeito não é mais uma identidade em essência, mas sim alguém em permanente reinvenção, inserido em múltiplas relações que enredam suas práticas.

Chartier (2009) entende que um texto não é uma simples abstração e que ele só existe graças à maneira como é transmitido. Os textos legitimam condutas e comportamentos, são suportes que se fazem ler, ouvir ou ver e produzem sentidos. Da 
mesma forma, combate a ideia do material escrito como objeto fixo, impossível de ser modificado e alterado pelas pessoas que interagem com ele. Para o autor, a leitura é sempre uma apropriação, uma invenção, uma produção de significados. Cada leitor atribui, assim, um sentido próprio ao que lê. Cada leitor, baseado em suas referências, "dá um sentido mais ou menos singular, mais ou menos partilhado aos textos de que se apropria." (CHARTIER, 2009, p. 20). A significação de um texto varia conforme as competências, as convenções, os usos e os protocolos de leitura próprios de cada comunidade. Assim, a leitura não se constitui em uma prática neutra. O leitor produz uma apropriação inventiva do texto que recebe. O livro Escola Primária Rural não era lido da mesma forma por todos os leitores. Alguns provavelmente eram interpelados pelos discursos, outros, talvez não. Cada sujeito é sujeito de uma variedade de discursos e pode aderir a eles ou não.

Pretende-se analisar, a seguir, alguns dos discursos que se apresentam no livro objeto deste estudo, especialmente as representações ${ }^{5}$ acerca das populações rurais, do professor rural e da escola.

\section{Início do livro: a oração da mestra}

Senhor, pois, que quiseste que o meu lar fosse a minha escola, que seja feita a Tua vontade [...]

Faze com que toda a manhã eu acorde de alma tranquila e coração puro, para buscar minha escola e encontrar meus filhos, de quem a noite inteira fui privada.

Que eu prepare nossa casa para recebê-los, como trouxe preparado, o ânimo para os acolher.

Que na hora tumultuosa em que entram, como aves inquietas no ninho, vá meu sorriso ao encontro deles e lhes diga, a todos, que os esperava. Um filho nunca é indiferente a dois braços maternos que se estendam para ele.

Faze com que eu não distinga entre eles se a sorte

${ }_{5}$ O conceito de representação identifica-se com a corrente historiográfica da História Cultural. Segundo Pesavento (2003, p. 39-40) "as representações construídas sobre o mundo não só se colocam no lugar deste mundo, como fazem com que os homens percebam a realidade e pautem sua existência (...) Representar é, pois, estar no lugar de, é presentificação de um ausente (...) não é uma cópia do real, sua imagem perfeita, mas uma construção feita a partir dele." os distinguiu pela beleza, pela saúde, pela cor, pelas vestes, pelas maneiras; que em minha companhia, em nossa escola, nem o pobre seja envergonhado, nem o vestido jactancioso. Faze que eu derrame igual maternidade sobre eles, para que sejam irmãos, ao menos na minha escola $[\ldots]$

Faze, Senhor, que cada um deles, desses meninos e meninas que na vida vão conhecer outras mulheres - mãe, irmã, parentas, esposa, filhas - possam, à lembrança das que forma dignas de amor - juntar a de sua mestra, que todo o bem lhes quis, de quem foram o grande amor da vida, com o amor de sua profissão. Amém. (AFRÂNIO PEIXOTO apud SILVA, 1951, p. 2).

O livro inicia com a Oração da Mestra destacado em forma de epígrafe. Apresenta os modos de ser que se esperavam de uma professora. É narrado na primeira pessoa do singular, o que personaliza o texto e contribui para promover a identificação com o seu conteúdo. Explicita virtudes e anseios de uma professora primária, indica um código de regras e de moral da profissão, valoriza posturas e ações corretas e, paralelamente, condena, mesmo que não diretamente, tantas outras atitudes. Serenidade, altruísmo, sacerdócio, abnegação, solidariedade, senso de justiça e amor materno são princípios que a professora deveria cultivar, isto é, deveriam fazer parte de sua personalidade.

O texto é dirigido a todas as professoras, tanto as que exerciam o magistério nas zonas urbanas, como aquelas que trabalhavam no meio rural. Isso mostra que, em muitos aspectos, as exigências profissionais eram as mesmas, o que era esperado de uma professora não dependia de onde ela fosse lecionar. É certo que todas deveriam ser capazes de se entregar profundamente à profissão escolhida, e isso, de certa forma, acentuava-se em relação ao magistério rural. Vida pessoal e vida profissional misturam-se e confundem-se na oração. As relações profissionais são invadidas por sentimentos e ações próprios da esfera privada das professoras. O local de trabalho comparado a casa, os alunos ocupam o lugar de filhos. Exigia-se da professora tamanha dedicação que extrapolava suas responsabilidades profissionais. Seu trabalho envolvia desprendimento e abnegação, a ponto de transferir sua vida íntima para a relação que mantinha com a escola. 
Não se deve esquecer o caráter religioso que envolve a narrativa, afinal trata-se de uma professora conversando com Deus. Dessa forma, os sujeitos professores eram moldados e constituídos, conhecedores da ética e moral da sua profissão, sabedores do que era certo e do que era errado, do que era permitido e do que a eles era negado. Com a epígrafe, Ruth parece querer mostrar os caminhos da profissão docente rural que deveriam ser trilhados por todos os professores.

\section{Representações do mundo rural}

As representações que foram construídas sobre o mundo rural constituíram-se verdadeiras forças de poder em que o mundo urbano, assumindo uma posição de superioridade, descaracterizava e, talvez, até mesmo se possa dizer, aniquilava os parâmetros culturais que eram as referências identitárias das populações campesinas. Todas essas representações não foram criadas aleatoriamente; tinham objetivos claros de reforçar a supremacia dos valores urbanos, colaborando para a construção de uma identidade nacional marcada pelos ideais de progresso e de modernidade, em que não havia espaço para o pluralismo de práticas e valores culturais distintos daqueles apregoados e difundidos nas cidades.

A educação rural apresentava-se como alternativa que se propunha a civilizar e recuperar as populações, ensinando-lhes a valorizar e trabalhar a terra, mas com um custo muito alto, pois alterava seus padrões culturais originais, implicando em um estreitamento de laços com os valores culturais urbanos.

Os discursos da época evidenciam muitas das representações que foram construídas sobre essas populações rurais. É com base nesse conjunto de representações que os objetivos da educação rural também foram construídos. De um modo geral, o homem rural era visto como alguém ignorante, atrasado, indolente, com uma cultura inferior, extremamente supersticioso, que precisava civilizar-se, que não sabia dispor de seu tempo de forma racional, não percebia a importância do progresso social, que não tinha conhecimento sobre alimentação adequada e hábitos de higiene e, por fim, desconhecia as vantagens da escolarização.
A autora vale-se de Fernando de Azevedo em A Cultura Brasileira e, por meio dessa referência, parafraseia o autor e apresenta uma série de representações referentes ao homem, à mulher e à criança do mundo rural, sempre estabelecendo analogias com os cidadãos urbanos. Inicialmente, apresenta uma que assim define a educação rural:

A questão da Educação Rural não é somente uma questão de interesse pedagógico, puramente técnico ou de caráter regional: ela é de uma grande complexidade e toca os interesses essenciais do País. Educação rural consiste em orientar as populações das zonas rurais no sentido da formação adequada ou conveniente às mesmas, vinculando-as ao meio e levando-as a reagir de modo eficiente sobre este. (AZEVEDO apud SILVA, 1951, p. 3).

Assim são definidas as características do homem rural:

O homem rural tem acentuado sentido de realidade, pensamento rico e concreto, pouco inclinado a divagações teóricas [...] embora religioso, muito inclinado à superstição; ingênuo na concepção da vida e do mundo, limitando-o quase ao próprio horizonte visual. Conserva muitas formas de pensamento primitivo, apesar das conquistas da ciência, para ele pouco ou nada difundidas. [...] é ainda o homem do campo rude no trato social e as suas manifestações estéticas são pouco frequentes, principalmente pela falta de cultura, expressando-as, de modo especial, pela música, uma de suas poucas formas de recreação [...] (SILVA, 1951, p. 13).

A mulher campesina também é comparada à mulher da cidade: A mulher campesina apresenta características semelhantes às da mulher da cidade, mas, muitas vezes, algumas de suas características femininas desaparecem quando desempenha tarefas semelhantes às do homem. (SILVA, 1951, p. 14).

São impressões por vezes preconceituosas, coerentes com os discursos circulantes na sociedade da época, que estabelecem distinções entre a população rural e urbana, colocando os primeiros em situação menos favorável, especialmente em termos culturais. Quando menciona a "falta de cultura" das populações rurais, Azevedo parece estar se referindo à ausência de uma cultura marcadamente urbana, como se só fossem válidas e apropriadas as manifestações culturais oriundas daquele espaço. $\mathrm{O}$ texto desconsidera os atributos culturais típicos das 
áreas rurais do país e sugere que as pessoas sejam formadas no intuito de conhecerem e valorizarem culturas mais "civilizadas" e "modernas", como aquelas praticadas nos meios urbanos. Percebem-se relações de poder que se colocam entre os mundos rural e urbano, tendo este posição hegemônica que lhe confere supremacia.

Nessa análise, a criança rural também é percebida de forma distinta da criança da cidade. Azevedo admite que a aprendizagem nas áreas rurais aconteça de forma mais lenta. Entretanto, registra e enfatiza a igualdade de inteligência entre crianças urbanas e rurais, tendo como parâmetro pesquisas feitas nos Estados Unidos. Talvez essa questão não estivesse totalmente esclarecida, havendo dúvidas quanto ao potencial intelectual dos alunos pertencentes às zonas agrárias; daí a necessidade de elucidá-la.

De um modo geral, a criança do campo é mais tenaz que a da cidade e o seu progresso intelectual é mais moroso; não é tão superficial e volúvel como a criança dos meios urbanos [...] Do ponto de vista da inteligência, em experiências realizadas nos Estados Unidos foi comprovado que a criança rural não é inferior à da cidade, embora apresente experiências diferentes e deficiências de linguagem. $[\ldots]$ quanto às características emocionais da criança rural, pode-se afirmar que esta, como a da cidade, necessita ajustar-se ao meio social a que pertence, para desenvolver todas as suas possibilidades e que $o$ desajustamento criar-lhe-á problemas, inclusive com relação à aprendizagem (SILVA, 1951, p. 15).

É possível que a intenção de Ruth tenha sido apresentar aos professores rurais uma espécie de perfil das pessoas com as quais iriam conviver em seu cotidiano. O professor, segundo esta visão, deveria estar atento e conhecer aqueles que estavam ao seu redor, fossem eles seus alunos, pais, enfim, todos da comunidade. Sabedor das características das pessoas, o professor teria maiores condições de intervir a fim de "moldar" melhor cada um deles, tendo como referências a urbanização, a ciência, a modernidade e o progresso.

\section{A luta pela educação rural}

$\mathrm{Na}$ sequência do segundo capítulo, a autora passa a centralizar o foco de análise para a escola rural e suas implicações na vida das comunidades a que pertencem. O professor, como agente fundamental no desenvolvimento educacional, também passa a ser enfatizado.

O discurso predominante no texto é de que a escola tem um grande papel a cumprir, de acordo com a visão do Estado, que atribui funções de extrema responsabilidade à educação. A escola deveria “civilizar sem urbanizar". Nas palavras da autora:

A escola primária de zona rural [...] tem necessariamente as mesmas finalidades da nossa escola comum, sendo sua função precípua a educação integral. Cabe-lhe oferecer um ensino que responda às necessidades e às características da vida regional, a fim de adaptar o indivíduo às realidades locais e fixálo no meio, capacitando-o a reagir vitoriosamente sobre o mesmo (SILVA, 1951, p. 17).

Nesse sentido, torna-se imprescindível a ação do professor rural a fim de que a escola consiga alcançar as metas a que se propõe. Ele é o ponto central de sustentação de toda política educacional. O aprendizado dos alunos, os cuidados com a sede da escola, o envolvimento com a comunidade, o desenvolvimento de projetos escolares e sociais, enfim, o êxito ou o fracasso educacional de cada escola dependem diretamente da atuação do professor. Este aspecto é assim abordado:

Realmente, o professor faz a sua escola, imprimindolhe o feitio de sua personalidade. Se ele estiver compenetrado de sua missão e imbuído desse espírito ruralista que será o vivificador de seu trabalho há de sobrar intuição para apreender em relances as necessidades do ensino, resolvendo-as satisfatoriamente (SILVA, 1951, p. 21).

Também o problema da formação profissional é enfocado. Defende-se que haja uma formação especializada para o magistério rural, com um currículo adaptado às necessidades do meio rural, sendo essa uma condição para o bom desempenho da profissão. Entretanto, "deve ser capacitado, sem ser um especialista para melhor servir ao meio". Continuando, o professor deve: "[...] ser preparado para exercer esta função, ou seja, receber formação profissional especializada, para que possa ter consciência das vantagens e das desvantagens e das dificuldades da mesma e orgulho da alta missão que está chamado a desempenhar" (SILVA, 1951, p. 24). 
Ruth Silva defende uma formação normal rural, com um currículo direcionado às exigências do meio rural a fim de que a escola primária rural consiga atingir seus objetivos.

É óbvio que o professor rural não precisa ser um sociólogo nem um técnico em agricultura; basta-lhe um quantum de conhecimentos gerais a e práticos nestes setores, com sólidos fundamentos para que possa perceber os problemas daí decorrentes e orientar-se , no melhor sentido, em busca de fontes necessárias, para a expansão e atualização dos mesmos. O tipo de mestre que se forma no ambiente urbano, desconhecendo a realidade da vida rural, poderá servir para as cidades, mas não convém, absolutamente, àquela zona (SILVA, 1951, p. 24-25).

As colocações da autora situam-se em uma perspectiva do que seria o ideal para o ensino nas zonas rurais, e conclui-se que a formação do professor rural era mais complexa que a do professor das cidades, pois ele precisava dominar conhecimentos que iam além dos saberes escolares tradicionais.

As dificuldades enfrentadas pelos docentes rurais também são exploradas no livro. Era comum trabalharem sozinhos, em comunidades isoladas, em ambientes hostis, e precisavam vencer resistências que porventura a comunidade oferecesse. As condições de moradia, alimentação e higiene, por vezes, eram deficientes. Além disso, há que se considerar a precariedade da sua formação pedagógica, somada a pouca maturidade de muitos deles para administrar os inúmeros entraves a que estavam expostos. Via de regra, esses docentes eram jovens, sem experiência alguma no magistério e, neste contexto, enfrentavam seus primeiros contatos com a profissão. Como técnica rural e conhecedora das características deste ambiente, certamente Ruth Silva tinha consciência dos problemas vividos nas escolas interioranas. Ainda que o texto insista na necessidade da adequada formação profissional, não omite questões relevantes acerca da profissão docente rural. Em uma dessas abordagens, a autora é enfática ao defender melhorias para o magistério rural:

Torna-se imprescindível também a reformulação da legislação [...] que atenda não só aos interesses do ensino, como aos problemas da formação e humanos do professor rural, oferecendo-lhe o estímulo de uma carreira com possibilidades de evoluir profissionalmente; oferecendo-lhe o estímulo de uma carreira com possibilidades de evoluir profissionalmente; oferecendo residência para o professor junto à mesma, o que lhe permite maior controle sobre as plantações e criações, como lhe proporciona o acolhimento de um lar e a liberdade de ação que não pode ter quando reside distante da escola ou em casa de família [...]; equipando a escola com um mínimo de instalações e material agrário [...] Que tenha água potável suficiente e instalações sanitárias adequadas ao meio, porém em condições higiênicas (SILVA, 1951, p. 20).

Ao analisar a quem as responsabilidades pela escola rural competem, Ruth Silva atribui funções diferenciadas para o Estado, os professores e a comunidade escolar. Destaca a importância da autonomia dos docentes para tomarem iniciativas que lhes pareçam as mais apropriadas nos locais em que trabalham: "Visamos, justamente, abolir o paternalismo antidemocrático, que anula iniciativas e adormece consciências" (SILVA, 1951, p. 20). Com relação ao papel do Estado, complementa: "[...] um mínimo inicial, porém, o primeiro núcleo, cabe ao Poder Público oferecer ao meio" (SILVA, 1951, p. 21). Nota-se a construção de um discurso que privilegia o trabalho docente, em detrimento de uma ação mais direta dos poderes públicos, especialmente quando diz:

Temos visto escolas que são apenas uma casa construída num descampado, sem uma árvore de sombra, sem uma horta, sem uma flor [...] Que triste exemplo de desolação e abandono! Poderá o professor, em tal escola, ser líder positivo da comunidade? Certo que não, se tudo vai esperar do Estado (SILVA, 1951, p. 21).

Reforça-se a ideia da importância da formação pedagógica e rural dos professores, no intuito de torná-los responsáveis pela solução do atraso agrário que vivia o país, por meio do aprimoramento da educação. Aos docentes deveriam ser oportunizados seminários, semanas de estudo, mesas redondas, painéis e outras técnicas; troca de experiências, entre outros. A eles cabia apropriarem-se dos discursos que eram difundidos para cumprirem sua tarefa com sucesso e "[...] terem orgulho da alta missão [...]" (SILVA, 1951, p. 23) a que estavam sendo chamados. 


\section{Didaticamente falando}

Os outros capítulos do livro, que são sua maior parte, apresentam planejamentos de aulas com atividades práticas específicas para cada uma das quatro séries do ensino primário, de acordo com as atividades econômicas da região escolar, fossem elas agrícolas, pastoris ou pesqueiras. Como diz a autora:

Damos a seguir várias sugestões de atividades de forma quase exaustiva, com o fim de enriquecê-las ao máximo. Nossa finalidade foi a de oferecer ao professor maiores oportunidades de escolha, considerando as ilimitadas variantes que a realidade das áreas rurais pode apresentar (SILVA, 1951, p. 51).

Ruth Silva enfatiza a importância de o professor fazer a sua investigação da realidade escolar na qual está inserido, estabelecendo um levantamento das necessidades e possibilidades locais e só após planejar as unidades didáticas. Isso evidencia sua preocupação para que o livro não se transformasse em uma espécie de "manual prescritivo", mas em um instrumento de consulta que exigia do docente a disponibilidade prévia para dedicar-se à pesquisa empírica em sua comunidade. Assim ela esclarece suas intenções:

Suponhamos que, entre outras, o professor verificou deficiências ou incorreções no sistema alimentar da comunidade. Cumpre-lhe, portanto, procurar saná-las ou atenuá-las. Neste caso, a difusão de conhecimentos teóricos e práticos sobre alimentação racional se impõe. Deverá o professor planejar uma unidade didática sobre alimentação na qual focalize os aspectos principais relativos ao assunto [...] (SILVA, 1951, p. 53).

A autora prossegue explicando como incluir as outras áreas do conhecimento neste planejamento:

Desta maneira, inúmeras e variadíssimas podem ser as unidades didáticas na escola, principalmente de zona rural, onde o professor tem maiores oportunidades de contato com o meio. As atividades escolares assim orientadas, além de vivificarem o trabalho de classe, levarão a escola a desempenhar a função social e civilizadora que lhe incumbe e de que tanto carecem nossas áreas rurais (SILVA, 1951, p.54).

O livro também apresenta atividades apropriadas para as escolas isoladas e outras que poderiam ser desenvolvidas nos grupos escolares. Nas escolas isoladas, sugere que se tenha uma unidade didática, por exemplo, a realização de uma horta escolar, e que se planejem atividades comuns ou específicas para cada série, pertinentes ao cultivo da horta. Já nos grupos escolares, os trabalhos podem ser diversificados, cada série pode desenvolver atividades rurais distintas. Assim, por exemplo, enquanto a primeira série trabalharia com a observação de animais e plantas úteis ao homem, a segunda série aprenderia técnicas de fruticultura e ficaria responsável pelo plantio do jardim da escola. A ênfase do texto é a fim de que as atividades rurais estivessem sempre integradas com os outros conteúdos fundamentais escolares.

A educação rural deveria contemplar três grandes eixos: a iniciação agrícola, o ensino primário fundamental, com os conteúdos básicos escolares e, por fim, também era função da educação promover uma orientação, a qual a autora chama de "prévocacional", a fim de preparar o aluno para futuras escolhas profissionais. Tal planejamento, posto em prática, ofereceria aos educandos um preparo para melhor aproveitarem os recursos e possibilidades da vida rural.

Ao analisar as diretrizes para desenvolvimento das atividades agrícolas na escola primária rural (SILVA, 1951, p. 55), sugere atividades comuns a todas as escolas rurais, tipo horticultura, jardinagem, independentemente da zona. Defende a importância de aulas em turno integral, valoriza a construção de clubes agrícolas, dedicando um capítulo do livro para explicar como se operacionalizam esses clubes nas escolas.

Ruth Silva salienta a importância de se considerar interesses, aptidões e motivações dos alunos, sua capacidade física e mental, da mesma forma que devem ser atendidos os aspectos relativos à aprendizagem, isto é, a didática especial das diversas matérias do currículo. Fala sobre o quanto é importante o professor ter clareza nos seus objetivos. Comenta as vantagens de usar o método do trabalho em equipe por ele melhor se prestar às condições práticas do desenvolvimento das atividades agrícolas/pastoris. Não descuida de um embasamento teórico, mas afirma que:

Sempre que se tornar indispensável o estudo teórico relativo à agricultura como uma preparação ao tra- 
balho prático deve se processar de forma simples e acessível, levando-se em conta as pesquisas bibliográficas a fim de que se forme na criança a ideia da necessidade de fundamento científico nos trabalhos agrícolas, combatendo-se a rotina dominante em nosso meio rural (SILVA, 1951, p. 27).

No planejamento do professor devem constar as finalidades, situações de aprendizagem, fixação da aprendizagem, verificação, documentação, atendendo a globalização do ensino.

\section{Considerações finais}

É provável que o livro analisado de Ruth Silva tenha sido o único editado no Rio Grande do Sul na década de 1950 que abordou especificamente o ensino rural nas primeiras séries escolares. A leitura da obra instigou a pesquisadora a perceber com mais atenção as particularidades e os detalhes que permeiam o contexto da educação rural, enfim, a leitura promoveu uma aproximação do universo da educação rural nas décadas passadas. Aqui se procurou historicizar a obra e cotejá-la com os parâmetros educacionais e econômicos dos anos 1950 e 1960 no Brasil. As propostas educacionais da autora revelam suas concepções políticas, econômicas e culturais, e isso permite identificar seu alinhamento aos ideais do ruralismo pedagógico e do escolanovismo. Neste sentido, vê-se que a autora conduz o leitor a acreditar no papel da escola redentora e no significado do trabalho do professor rural com as populações campesinas, tendo em vista o abandono em que se encontravam, uma vez que os investimentos públicos concentravam-se no modelo de urbanização emergente no país.

$\mathrm{O}$ livro ensina um modo de ser dos professores rurais, constituindo-se, portanto, uma estratégia educativa por promover a adesão dos sujeitos a determinados discursos.

Passados quase 60 anos da primeira edição da obra de Ruth Silva, ainda são muitos os desafios da educação rural no nosso país. Em tempos de crescente globalização econômica e cultural, em que a população urbana é significativamente maior que a rural e a tendência é o apagamento de diferenças, questiona-se a viabilidade de uma educação propriamente rural.

As lutas que mobilizavam Ruth Silva e tantos outros adeptos ao ruralismo pedagógico continuam, sob certo aspecto, atuais, tendo em vista que persiste no país a exclusão de muitos do acesso à escolarização. A hegemonia que caracteriza a urbanidade praticamente acaba por anular aqueles e aquelas que vivem com outras referências, que ainda são, muitas vezes, ignorados pelas políticas públicas educacionais.

Para finalizar, acredita-se que o livro de Ruth Silva cumpriu um papel importante em seu tempo, especialmente considerando a orientação aos docentes e a defesa explícita de uma escola primária rural de qualidade numa época em que o pensamento pedagógico comumente atendia a outras demandas, que não eram as mesmas das escolas do interior.

\section{REFERÊNCIAS}

ALMEIDA, Dóris Bittencourt. A educação rural como um processo civilizador. In: STEPHANOU, Maria; BASTOS, Maria Helena Câmara (Orgs.). Histórias e memórias da educação no Brasil: século XX. Petrópolis: Vozes, 2004. v.3. p. 278-295.

Vozes esquecidas em horizontes rurais: histórias de professores. Rio Grande do Sul, 2001. Dissertação (Mestrado em Educação) - Programa de Pós-Graduação em Educação, Universidade Federal do Rio Grande do Sul, Porto Alegre, 2001.

CHARTIER, Roger (Org.). Práticas da leitura. São Paulo: Estação da Liberdade, 2009.

CUNHA, Maria Teresa Santos. Nas margens do instituído: memória/educação. Revista História da Educação, Pelotas, n. 5, p. 23-38, abr. 1999.

GHIRARDELLI JR., Paulo. História da Educação. São Paulo: Cortez, 1995.

MENESES, Ulpiano T. Bezerra de. A crise da memória, história e documento: reflexões para um tempo de transformações. In: SILVA, Zélia Lopes (Org.). Arquivos, patrimônio e memória. São Paulo: UNESP: FAPESP, 1999. p. 11-29. 
NAGLE, Jorge. Educação e sociedade na Primeira República. São Paulo: EPU, 1974.

PESAVENTO, Sandra Jatahy. História \& História Cultural. Belo Horizonte: Autêntica, 2003.

PINTO, Celi Regina Jardim. Com a palavra o senhor Presidente José Sarney: o discurso do Plano Cruzado. São Paulo: Hucitec, 1989.

SILVA, Ruth Ivoty Torres da. Educação primária rural. Porto Alegre: Globo, 1951.

SOTO, William Héctor Gómez. A produção do conhecimento sobre o "mundo rural" no Brasil: as contribuições de José de Souza Martins e José Graziano da Silva. Santa Cruz do Sul: EDUNISC, 2002.

Fontes consultadas:

REVISTA DO ENSINO DO ESTADO DO RIO GRANDE DO SUL, 1951, n.7.

ENTREVISTA com José Otávio Bertaso. Porto Alegre : Globo, 2002.

Recebido em 24.06.2011

Aprovado em 14.08.2011 